ARTICLE

\title{
Local and global crosstalk among heterochromatin marks drives DNA methylome patterning in Arabidopsis
}

Taiko Kim To 1,2雨, Chikae Yamasaki ${ }^{1}$, Shoko Oda ${ }^{1}$, Sayaka Tominaga ${ }^{1}$, Akie Kobayashi ${ }^{2}$, Yoshiaki Tarutani $^{2}$ \& Tetsuji Kakutani (10) ${ }^{1,2}$ 瓜

Transposable elements (TEs) are robustly silenced by multiple epigenetic marks, but dynamics of crosstalk among these marks remains enigmatic. In Arabidopsis, TEs are silenced by cytosine methylation in both $\mathrm{CpG}$ and non- $\mathrm{CpG}$ contexts ( $\mathrm{mCG}$ and $\mathrm{mCH}$ ) and histone $\mathrm{H} 3$ lysine 9 methylation ( $\mathrm{H} 3 \mathrm{~K} 9 \mathrm{me}$ ). While $\mathrm{mCH}$ and $\mathrm{H} 3 \mathrm{~K} 9 \mathrm{me}$ are mutually dependent for their maintenance, $\mathrm{mCG}$ and $\mathrm{mCH} / \mathrm{H} 3 \mathrm{~K} 9 \mathrm{me}$ are independently maintained. Here, we show that establishment, rather than maintenance, of $\mathrm{mCH}$ depends on $\mathrm{mCG}$, accounting for the synergistic colocalization of these silent marks in TEs. When mCG is lost, establishment of $\mathrm{mCH}$ is abolished in TEs. $\mathrm{mCG}$ also guides $\mathrm{mCH}$ in active genes, though the resulting $\mathrm{mCH} / \mathrm{H} 3 \mathrm{~K} 9 \mathrm{me}$ is removed thereafter. Unexpectedly, targeting efficiency of $\mathrm{mCH}$ depends on relative, rather than absolute, levels of $\mathrm{mCG}$ within the genome, suggesting underlying global negative controls. We propose that local positive feedback in heterochromatin dynamics, together with global negative feedback, drive robust and balanced DNA methylome patterning.

\footnotetext{
${ }^{1}$ Department of Biological Sciences, The University of Tokyo, Tokyo 113-0033, Japan. ${ }^{2}$ Department of Integrated Genetics, National Institute of Genetics, Mishima, Shizuoka 411-8540, Japan.凶email: tkt@bs.s.u-tokyo.ac.jp; tkak@bs.s.u-tokyo.ac.jp
} 
arge genomes of vertebrates and plants contain substantial amounts of transposable elements (TEs) and their derivatives. As TEs are a potential threat to genome stability and proper gene expression, they are silenced by epigenetic mechanisms such as cytosine methylation and histone $\mathrm{H} 3$ methylation at lysine 9 $(\mathrm{H} 3 \mathrm{~K} 9 \mathrm{me})^{1-4}$. In plant genomes, methylated cytosines are enriched in TEs for both CpG and non-CpG (or $\mathrm{CpH}$, where $\mathrm{H}$ can be $\mathrm{A}, \mathrm{T}$, or C) contexts,6. In Arabidopsis, methylation at CpG sites (mCG) is maintained by a DNA methyltransferase (MTase) called MET1 (METHYLTRANSFERASE 1$)^{7,8}$. Methylation at $\mathrm{CpH}$ sites $(\mathrm{mCH})$ is catalyzed by another class of DNA MTases, CHROMOMETHYLASE 2 and 3 (CMT2 and CMT3) $^{9-12}$. Within $\mathrm{mCH}$, symmetric $\mathrm{mCHG}$ and asymmetric $\mathrm{mCHH}$ are often analyzed separately, because their controls are different; $\mathrm{mCHG}$ is catalyzed by CMT3 and CMT2, while $\mathrm{mCHH}$ is catalyzed by $\mathrm{CMT} 2^{11,12}$. These CMTs are recruited to regions with $\mathrm{H} 3 \mathrm{~K} 9 \mathrm{me}$. $\mathrm{H} 3 \mathrm{~K} 9 \mathrm{me}$ is catalyzed by SUVH4, SUVH5, and SUVH6, and these H3K9 MTases, in turn, are recruited to regions with $\mathrm{mCH}^{10,13,14}$, generating a self-reinforcing positive feedback loop ${ }^{15}$. By this positive feedback, $\mathrm{mCH}$ and $\mathrm{H} 3 \mathrm{~K} 9 \mathrm{me}$ are maintained through cell divisions.

While $\mathrm{H} 3 \mathrm{~K} 9 \mathrm{me}$ and $\mathrm{mCH}$ depend on each other, their relationship to $\mathrm{mCG}$ has received less attention. Mutations in the CpG MTase gene MET1 have only minor effects on $\mathrm{mCH}$ and H3K9me; similarly, mutations in $\mathrm{CpH}$ MTases CMTs or H3K9 MTases SUVHs also have only minor effects on mCG $^{5,6,13,16-18}$. Thus, these two layers of modifications are maintained largely independently.

Although the two layers of modifications, mCG, and $\mathrm{mCH} /$ $\mathrm{H} 3 \mathrm{~K} 9 \mathrm{me}$, are maintained independently, they are associated with each other during de novo establishment. This association in the establishment can be seen in both RNAi-dependent and -independent pathways. Plants can methylate both $\mathrm{CpG}$ and $\mathrm{CpH}$ sites in an RNAi-based pathway, called RdDM (RNA-directed DNA methylation). RdDM is a mechanism to trigger mCG and $\mathrm{mCH}$ by de novo DNA MTase DRM2, and its targeting depends on siRNAs and siRNA-associating RNAi components ${ }^{19,20}$. In addition to this well-investigated RNAi-based pathway, we have recently identified a very robust and precise RNAi-independent pathway to establish $\mathrm{mCH}$ and $\mathrm{H} 3 \mathrm{~K} 9 \mathrm{me}$ de novo in coding regions of TEs (TE genes); both $\mathrm{H} 3 \mathrm{~K} 9 \mathrm{me}$ and $\mathrm{mCH}$ are lost simultaneously in mutants for SUVHs or CMTs, but these marks recover efficiently and precisely in coding regions of TEs (TE genes) after reintroduction of the wild-type alleles ${ }^{18}$. Unexpectedly, this recovery of $\mathrm{mCH} / \mathrm{H} 3 \mathrm{~K} 9 \mathrm{me}$ is independent of the RNAibased de novo DNA methylation machinery, such as DRM2 or RNA-dependent RNA polymerases. However, the recovery is inefficient in TE genes that have lost mCG. These results suggest that mCG might induce de novo establishment of $\mathrm{mCH}$ and $\mathrm{H} 3 \mathrm{~K} 9 \mathrm{me}$ in the RNAi-independent pathway, although the causative link between them remains to be tested.

Although both mCG and $\mathrm{mCH} / \mathrm{H} 3 \mathrm{~K} 9 \mathrm{me}$ are enriched in TEs, their distribution patterns differ in active genes. In addition to TEs, about $20 \%$ of active genes have $\mathrm{mCG}$ in their internal regions (gene bodies) ${ }^{21-24}$. In contrast, $\mathrm{mCH}$ and $\mathrm{H} 3 \mathrm{~K} 9 \mathrm{me}$ are found almost exclusively in TEs ${ }^{5,6}$. A factor contributing to the exclusion of $\mathrm{mCH} / \mathrm{H} 3 \mathrm{~K} 9 \mathrm{me}$ from active genes is a Jumonji domain-containing histone demethylase gene, INCREASE IN BONSAI METHYLATION 1 (IBM1) $25-27$; in ibm1 mutants, $\mathrm{H} 3 \mathrm{~K} 9 \mathrm{me}$ and $\mathrm{mCH}$ accumulate in expressed genes. Interestingly, the genic $\mathrm{H} 3 \mathrm{~K} 9 m e$ and $\mathrm{mCH}$ in the $i b m 1$ mutant background are found in genes with body $\mathrm{mCG}^{27}$. Thus, $\mathrm{mCG}$ might direct de novo $\mathrm{mCH}$ in genes, as well as in TEs. However, a causative link between $\mathrm{mCG}$ and $\mathrm{mCH} / \mathrm{H} 3 \mathrm{~K} 9 \mathrm{me}$ remains to be examined in genes as well as in TEs.

Here, we directly examine whether mCG is necessary for the establishment of $\mathrm{mCH}$ by using a mutation of $\mathrm{CpG}$ MTase gene
MET1. The results reveal that TE genes that lose mCG by the met 1 mutation fail to establish $\mathrm{mCH}$. In addition to the effect on TE genes, the met1-induced loss of mCG compromises genic $\mathrm{mCH}$ accumulating in the background of $i b m 1$ mutant. Unexpectedly, the targeting efficiency of genic $\mathrm{mCH}$ depends on relative level of mCG within the genome, rather than the absolute levels of mCG. This effect is seen in the mCG-directed $\mathrm{mCH}$ for both active genes and $\mathrm{TE}$ genes. In addition, $\mathrm{mCH}$ in $\mathrm{TE}$ genes and the ibm1-induced genic $\mathrm{mCH}$ affect each other negatively, suggesting global negative feedback in the heterochromatin dynamics. Based on these and previous results, we propose that global negative feedback and local positive feedback of heterochromatin marks, combined with H3K9 demethylation in active genes, results in robust and balanced differentiation of silent and active genomic regions.

\section{Results}

Loss of MET1 function abolishes establishment of $\mathrm{mCH}$ in TE genes. Because $\mathrm{mCH}$ and $\mathrm{H} 3 \mathrm{~K} 9 \mathrm{me}$ depend on each other, both modifications are lost both in the $\mathrm{cmt} 2 \mathrm{cmt} 3$ double mutant of the $\mathrm{mCH}$ MTase genes (hereafter referred to as $c c$ ) and in the suvh4 suvh5 suvh6 triple mutant of the H3K9 MTase genes (hereafter referred to as sss). The F1 progeny between these mutants inherited genomes without $\mathrm{H} 3 \mathrm{~K} 9 \mathrm{me}$ and $\mathrm{mCH}$, but all these mutated genes (CMTs and SUVHs) are complemented by functional wild-type alleles in heterozygous states in the F1 (Fig. 1a). We previously showed that, in the $\mathrm{F} 1$ progenies, $\mathrm{mCH}$ and $\mathrm{H} 3 \mathrm{~K} 9 \mathrm{me}$ recover efficiently despite their absence in the parents (Fig. 1a, c, i) ${ }^{18}$. This efficient recovery is independent of RNAi but inefficient in TE genes that lack mCG at the transcription start site.

To directly investigate the possible contribution of $\mathrm{mCG}$ to the establishment of $\mathrm{mCH}$, we conducted the same genetic experiments in the mutant background of $\mathrm{CpG}$ methyltransferase gene MET1 (Fig. 1b). We used the incomplete loss-of-function allele, met $1-1^{28}$, because the null allele of met 1 mutants in combination with $\mathrm{mCH}$ mutants results in severe developmental defects and infertility ${ }^{29}$. We generated the met1-1 cmt2 cmt3 and the met1-1 suvh 4 suvh 5 suvh 6 mutants (hereafter referred to as mcc and msss, respectively) and performed a genetic cross between them to obtain the F1 plants (hereafter we call them as $m \mathrm{~F} 1$; Fig. $1 \mathrm{~b}$ ), which can be compared to the original F1 plants between $c c$ and sss (Fig. 1a). In contrast to the efficient recovery of $\mathrm{mCH}$ in $\mathrm{F} 1$ in the wild-type MET1 background (Fig. $1 \mathrm{c}, \mathrm{d}, \mathrm{i}, \mathrm{j}$ ), the $m \mathrm{~F} 1$ plants showed severe defects in the restoration of $\mathrm{mCH}$ in $\mathrm{TE}$ genes for both $\mathrm{CHG}$ (Fig. 1e-h) and $\mathrm{CHH}$ (Fig. 1k-n) contexts.

Loss of $\mathbf{m C G}$ is associated with loss of $\mathbf{m C H}$ recovery. Next, we examined if the failure of $\mathrm{mCH}$ recovery in the $m \mathrm{~F} 1$ was associated with the loss of mCG. Because met1-1 is an incomplete loss-of-function allele, mCG remains in many, although not all, of TE genes ${ }^{28,30}$ (Supplementary Fig. 1a). Likewise, some TE genes kept $\mathrm{mCG}$ in the $m c c, m s s s$, and the $m \mathrm{~F} 1$ (Supplementary Fig. 1a). Thus, we compared the residual $\mathrm{mCG}$ and the efficiency of $\mathrm{mCH}$ recovery in the $m \mathrm{~F} 1$. Indeed, $\mathrm{mCH}$ recovery was found where mCG remains (Fig. 2a, b; Supplementary Fig. 2a, b; Supplementary Fig. $3 \mathrm{a}-\mathrm{c}$ ). The residual mCG of the TE genes in the $m \mathrm{~F} 1$ is proportionally associated with their $\mathrm{mCH}$ recovery (Fig. $2 \mathrm{c}, \mathrm{d}$ ). TE genes with loss of $\mathrm{mCG}$ did not recover $\mathrm{mCH}$ (Fig. 2d), further demonstrating the contribution of mCG to $\mathrm{mCH}$ establishment. In addition, although the simultaneous loss of mCG and $\mathrm{mCH}$ in msss or mcc mutants results in transcriptional derepression in many $\mathrm{TE}$ genes, the mCG-dependent $\mathrm{mCH}$ recovery in the $m \mathrm{~F} 1$ (Fig. $2 \mathrm{~d}$ ) induces robust re-silencing of them 
a

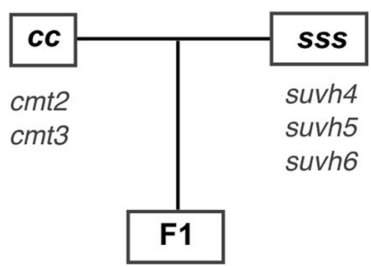

Heterozygous for the five mutations in CMT and SUVH genes. b

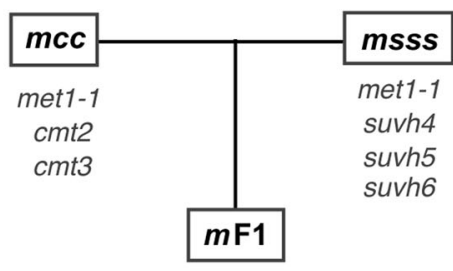

Heterozugous for the mutations in CMT and SUVH genes in homozygous met1-1 mutant background

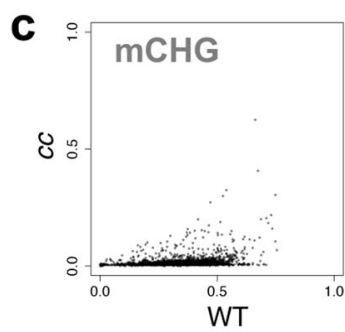

e
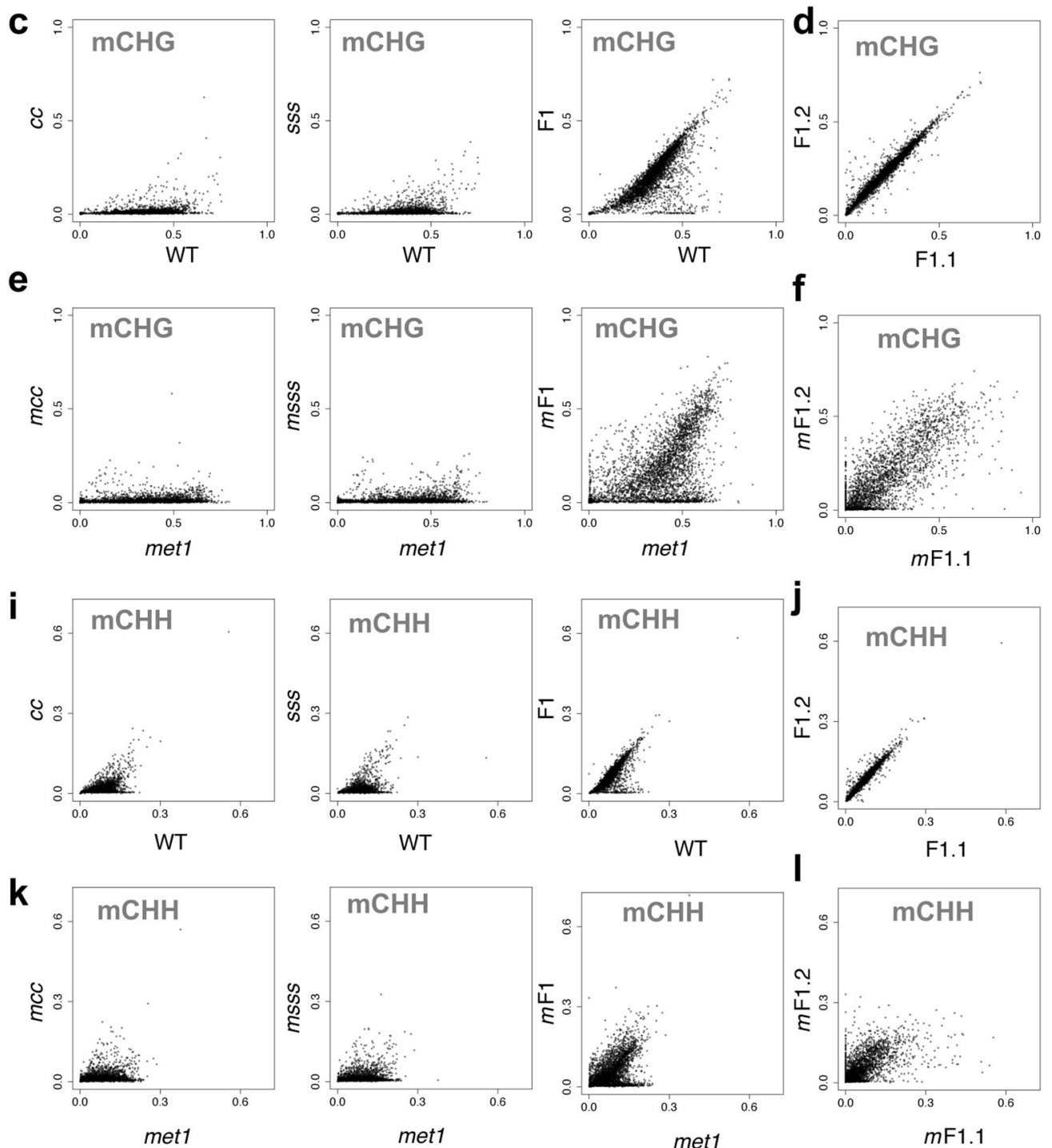

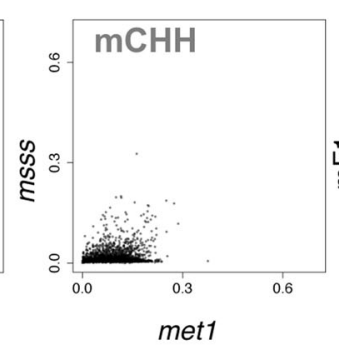

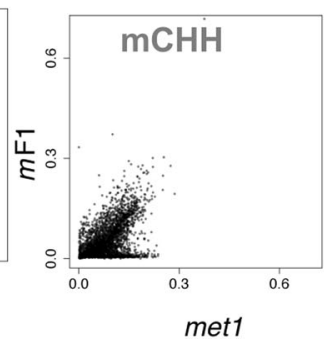
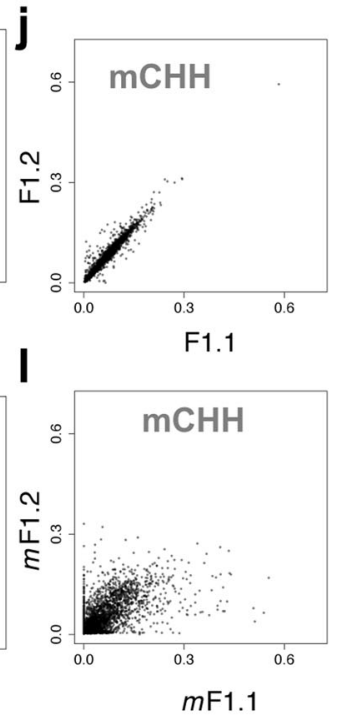

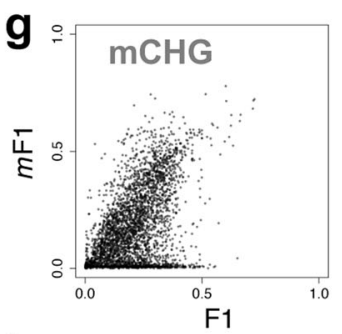

h
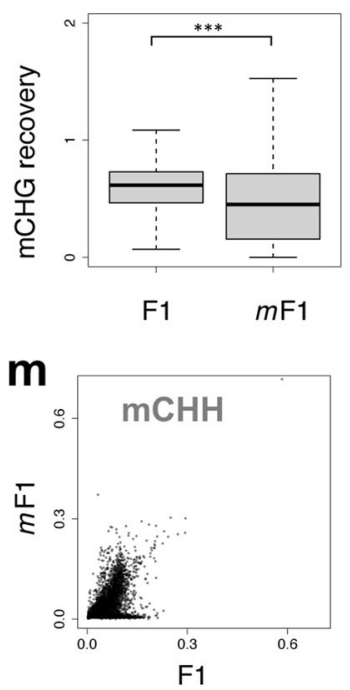

n

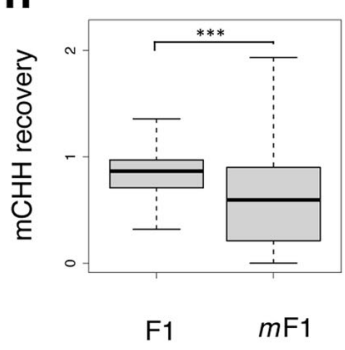

(Fig. 2e), demonstrating the importance of recovered $\mathrm{mCH}$ in $\mathrm{TE}$ silencing.

Genic $\mathrm{mCH}$ is directed to regions with relatively high levels of mCG. Next, we asked if $\mathrm{mCG}$ in genes also affects their $\mathrm{mCH}$. In wild-type plants, $\mathrm{H} 3 \mathrm{~K} 9 \mathrm{me} 2$ and $\mathrm{mCH}$ are excluded from genes and that depends on the histone demethylase IBM1; in the $i b m 1$ mutant, $\mathrm{H} 3 \mathrm{~K} 9 \mathrm{me} 2$, as well as $\mathrm{mCH}$, accumulate in genic regions ${ }^{25-27}$. Importantly, the genic $\mathrm{mCH}$ in the $i b m 1$ mutant correlates with the presence of $\mathrm{mCG}^{26,27}$. To see if $\mathrm{mCG}$ in gene bodies is responsible for the $\mathrm{mCH}$ in the $i b m 1$ background, we generated the double mutants of met1-1 and ibm1-4 (Fig. 3a, bottom left, met1 ibm1, hereafter referred to as $\mathrm{mi}$ ) and examined the effect of the met 1 mutation on $i b m 1$-induced genic $\mathrm{mCH}$ accumulation. In both met1-1 and mi plants, genic mCG was drastically reduced, but they still had some residual mCG (Fig. 3b, top panel; Supplementary Fig. 1b; Supplementary Fig. 4). Unexpectedly, although the genic $\mathrm{mCG}$ is low in the mi mutant, a significant increase of genic $\mathrm{mCH}$ was detected (Fig. 3b, middle and bottom panels; Supplementary Fig. 4). Nonetheless, the genic $\mathrm{mCH}$ in $m i$ plants correlated with levels of their residual mCG (Fig. $3 \mathrm{c}-\mathrm{e}$ ), suggesting that the relative, rather than absolute, level of $\mathrm{mCG}$ within the genome is critical. In other words, $\mathrm{mCH}$ is targeted to regions with $\mathrm{mCG}$, but this targeting seems much enhanced when $\mathrm{mCG}$ levels are low in the other regions of the genome. The spectrum of $\mathrm{mCH}$ and $\mathrm{mCG}$ in $m i$ plants differed 
Fig. 1 Loss of MET1 function abolishes establishment of $\mathbf{m C H}$ in TE genes. a, b Scheme of genetic crosses. Mutant of $\mathrm{CpH}$ MTases (cmt2 cmt3: $\mathrm{cc}$ ) and mutant of H3K9 MTases (suvh4 suvh5 suvh6: sss) were crossed to generate F1, which are heterozygous for all the mutated genes (a). The analogous cross was done between FO of met1-1 mutant background (mcc and msss) to generate F1 with homozygous met7-1 mutation ( $m$ F1) (b). c mCHG recovery in the F1. mCHG level of each TE gene in the mutants, cc (left), sss (middle), and the F1 (right), compared to a wild-type plant (WT). The results are reproduction of published results (GSE148753 ${ }^{18}$ ). d A comparison of $\mathrm{mCHG}$ between the two individual F1 plants. e mCHG recovery in the $\mathrm{mF1}$. $\mathrm{mCHG}$ level of each TE gene in the mutants $m c c$ (left), msss (middle), and the $m F 1$ (right) compared to a met1-1 mutant. $\mathbf{A}$ A comparison of $m C H G$ between the two individual $m F 1$ plants. $\mathbf{g}$ A comparison of $\mathrm{mCHG}$ level between the $\mathrm{F} 1$ and $m \mathrm{~F} 1$ plants. $\mathbf{h}$ Comparison of the efficiency of $\mathrm{mCHG}$ recovery in $\mathrm{F} 1$ and $m \mathrm{~F} 1$ plants ( ${ }^{\star \star \star} P<0.0001$, Wilcoxon signed-rank test, two-sided). The efficiency of recovery was calculated as F1/WT and $m F 1 / m e t 1$, respectively. To avoid division by values near zero, TE genes with $\mathrm{mCHG}(>0.1)$ in both WT and met1 mutant were used $(n=3212)$. Outliers are not shown. The centerline and box edges represent quartiles and whiskers range 1.5 times of the interquartile from the box edges. $\mathbf{i}-\mathbf{m} \mathbf{m C H H}$ recovery of TE genes in the $\mathrm{F} 1$ and $m \mathrm{~F} 1$ in the format of (c)-(g), respectively. $\mathbf{n}$ Comparison of the efficiency of $\mathrm{mCHH}$ recovery in $\mathrm{F} 1$ and $m \mathrm{~F} 1$ plants $\left({ }^{\star \star} \mathrm{P}<0.0001\right.$, Wilcoxon signed-rank test, two-sided). The efficiency of recovery was calculated as F1/WT and $\mathrm{mF1} /$ met1, respectively. To avoid division by values near zero, $\mathrm{TE}$ genes with $\mathrm{mCHH}(>0.03)$ in both WT and met1 mutant were used $(n=2915)$. Outliers are not shown. The original data for WT, cc, sSs and F1 are from GSE148753 ${ }^{18}$. The centerline and box edges represent quartiles and whiskers range 1.5 times of the interquartile from the box edges. Source data underlying Fig. 1 are provided as a Source Data file.

from that in $i b m 1$ plants and the spectrum differed even between different $m i$ individuals (Supplementary Fig. 5a-c; Supplementary Fig. 6). Importantly, the genic $\mathrm{mCH}$ in each of $m i$ plants correlated best with mCG level of the same plant but much less to those of the other plants (Fig. 3f; Supplementary Fig. 5d), suggesting that targeting of $\mathrm{mCH}$ is controlled by $\mathrm{mCG}$, rather than other intrinsic properties of each gene.

Association of genic $\mathrm{mCG}$ and $\mathrm{mCH}$ in epigenetic variant individuals. $\mathrm{mCH}$ accumulated preferentially in genes with relatively high levels of $\mathrm{mCG}$ in $m i$ as in $i b m 1$ single mutant plants. Unexpectedly, however, the level of $\mathrm{mCG}$ required for the accumulation of $\mathrm{mCH}$ seems much lower in $m i$ than that in $i b m 1$; 0.1 of $\mathrm{mCHG}$ was achieved when genes have about 0.04 of mCG level in $m i$, while more than 0.3 of mCG level in ibm 1 single mutant (Fig. 3d). One possible explanation for the difference is that it is attributable to the global reduction of $\mathrm{mCG}$ in met 1 background; in other words, the accumulation of genic $\mathrm{mCH}$ in $i b m 1$ mutant background may depend on the relative, rather than absolute, level of mCG. If the relative amount of $\mathrm{mCG}$ is really critical for the $\mathrm{mCH}$, local loss of $\mathrm{mCG}$ is expected to show a clearer and stronger effect. We next tested this hypothesis using materials with local and heritable loss of mCG, as stated below.

In plants, variations in mCG patterns tends to be transmitted stably over generations ${ }^{31-34}$. That results in heritable loss of genic mCG detected among wild-type MET1/MET1 siblings in the progeny of $M E T 1 /$ met 1 heterozygotes, and the spectrum of $\mathrm{mCG}$ loss is variable among individuals ${ }^{35,36}$. Consistent with these previous results, loss of genic $\mathrm{mCG}$ was detected in the MET1/MET1 ibm1/ibm1 plants (hereafter referred to as $M i$ ) originated from $M E T 1 / m e t 1-1 \mathrm{IBM} 1 / \mathrm{ibm} 1$ double-heterozygotes (Fig. 3a, bottom right and Supplementary Fig. 1c), and the spectrum and degree of mCG differed among individual $M i$ plants (Fig. 4a). We used such heritable mCG variation among individuals to examine the association between local mCG loss and the ectopic $\mathrm{mCH}$ seen in the $i b m 1$ mutants.

In the two Mi siblings, genes with high mCG in only one of the two individuals (red and blue in Fig. 4a) show specific accumulation of $\mathrm{mCH}$ in that individual (Fig. 4b, c; Supplementary Fig. $6 \mathrm{~b}, \mathrm{c}$ ). In addition, genes with low mCG in both of the two individuals (green in Fig. 4a) show a consistent lack of $\mathrm{mCH}$ accumulation (Fig. 4b; Supplementary Fig. 6c). These results further demonstrate that genic $\mathrm{mCH}$ detected in the absence of $I B M 1$ function depends on $\mathrm{mCG}$.

mCH is controlled not only locally but also globally. The results above indicate that the relative, rather than the absolute, mCG level is critical for targeting of genic $\mathrm{mCH}$ seen in the $i b m 1$ mutant background. The mCH levels may be controlled by a global negative feedback mechanism, which would explain the significant genic $\mathrm{mCH}$ in $m i$ plants despite its low mCG. Analogous effects can also be detected in the mCG-directed $\mathrm{mCH}$ of the TE genes in $m \mathrm{~F} 1$. In $m \mathrm{~F} 1, \mathrm{mCH}$ recovery was more efficient in TE genes with a relatively high level of $\mathrm{mCG}$ (Fig. 2c, d); and interestingly, in these TE genes with a relatively high level of $\mathrm{mCG}, \mathrm{mCH}$ recovery tend to be more efficient in $m \mathrm{~F} 1$ than in $\mathrm{F} 1$ (Fig. $2 \mathrm{~d}$, middle and right), despite less $\mathrm{mCG}$ in $m \mathrm{~F} 1$ than in $\mathrm{F} 1$ (Fig. 2d, left). We further examined properties of TE genes with significantly higher $\mathrm{mCH}$ in $m \mathrm{~F} 1$ than in F1 (TE genes colored in blue in Supplementary Fig. 3a, b); importantly, the efficient $\mathrm{mCH}$ recovery in $m \mathrm{~F} 1$ coincides with the fact that these TE genes have a relatively high level of mCG within the $m \mathrm{~F} 1$ genome, but not within the F1 genome (Supplementary Fig. 3d, "rank" panel). Thus, global negative feedback seems to function for $\mathrm{mCG}$-directed $\mathrm{mCH}$ in both active genes and $\mathrm{TE}$ genes.

In agreement with this interpretation, we have previously reported results suggesting global negative feedback to control heterochromatin marks, using another Arabidopsis mutant $d d m 1$ (decrease in DNA methylation 1$)^{11,37,38}$. The ddm1 mutation induces loss of $\mathrm{mCG}$ and $\mathrm{mCH}$ in heterochromatic TE genes ${ }^{11}$. The $d d m 1$-induced loss of $\mathrm{mC}$ in TEs is associated with ectopic and stochastic gain of $\mathrm{mC}$ in other loci including genic regions ${ }^{39,40}$. Importantly, the descendants from a cross between $d d m 1$ and wild-type plants in wild-type DDM1 genotype (i.e. $d d m 1$-epiRIL) show the ectopic methylation even in regions originating from wild-type DDM1 parents. This ectopic methylation correlates with the amount of chromosome regions inherited from the $d d m 1$ parent, further demonstrating that loss of DNA methylation in TE genes induces genic $\mathrm{mCH}$ in trans $^{40}$. The ectopic $\mathrm{mCH}$ is also induced in a met 1 mutant ${ }^{32}$, consistent with the idea that global loss of mCG accelerates targeting of $\mathrm{mCH} /$ H3K9me machinery via a global negative feedback mechanism.

Negative interaction could also be detected between $\mathrm{mCH}$ in TE genes and the $i b m 1$-induced genic $\mathrm{mCH}$. Gain of genic $\mathrm{mCH}$ in $i b m 1$ mutant induced reduction of $\mathrm{mCH}$ in TE genes (Fig. 5a; Supplementary Fig. 7a). In the $i b m 1$ mutant, the genic $\mathrm{mCH}$ accumulate progressively over generations ${ }^{40,41}$, and the reduction of $\mathrm{mCH}$ in TE genes in ibml was also progressive over generations (Fig. 5a; Supplementary Fig. 7a), consistent with the idea that $\mathrm{mCH}$ levels are controlled globally by negative feedback. As the opposite direction of interaction, we also examined if $d d m 1$-induced loss of $\mathrm{mCH}$ in TE genes affects $i b m 1$-induced genic $\mathrm{mCH}$. Indeed, the genic $\mathrm{mCH}$ in $i b m 1$ mutation was much enhanced in the $d d m 1 i b m 1$ double mutant (Fig. 5b, c; Supplementary Fig. 7b, c). Taken together, these results suggest that $\mathrm{mCH}$ levels are controlled by global negative feedback. 
a

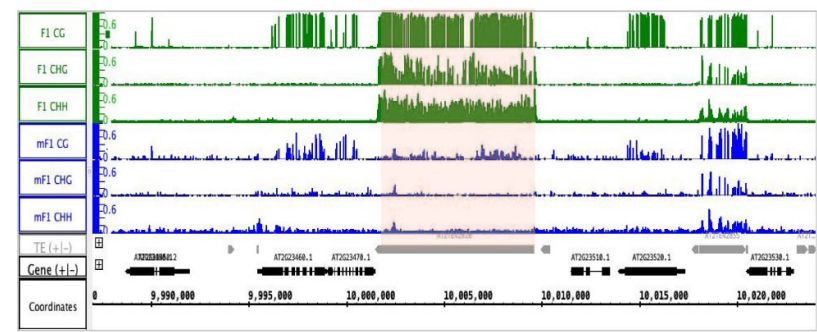

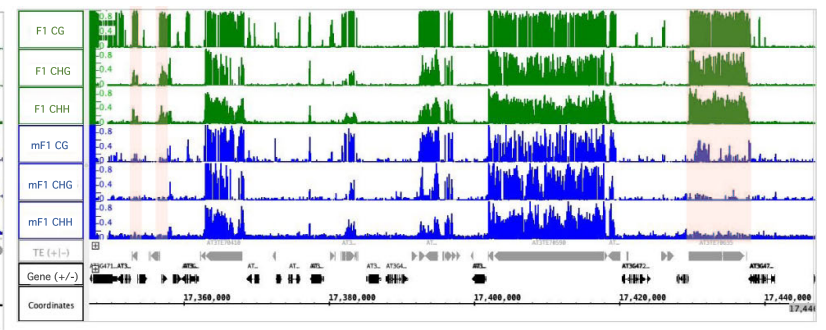

b

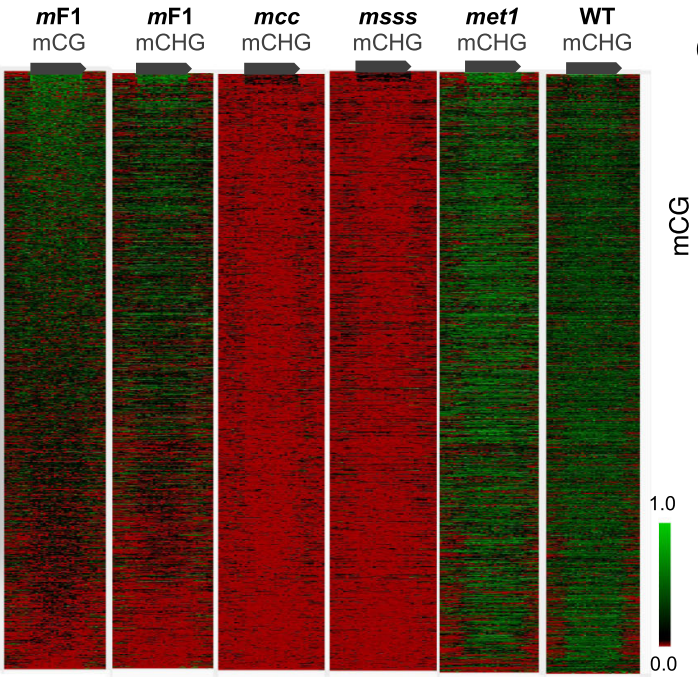

C
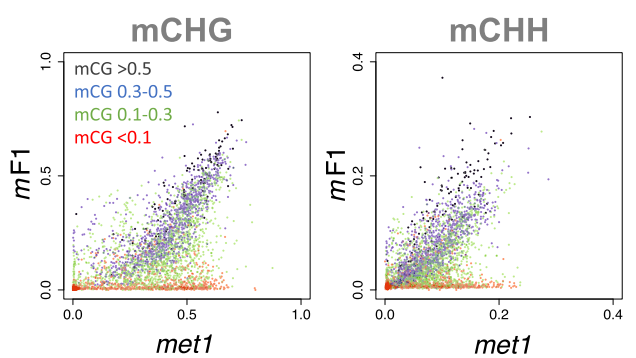

d

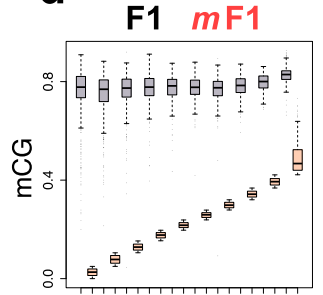

F1 $m \mathrm{~F} 1$

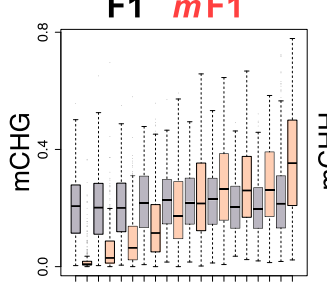

Decile ranked by $\mathrm{mCG}$ in $m \mathrm{~F} 1$
F1 $m \mathrm{~F} 1$

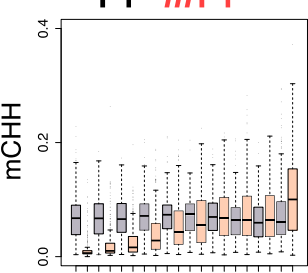

e
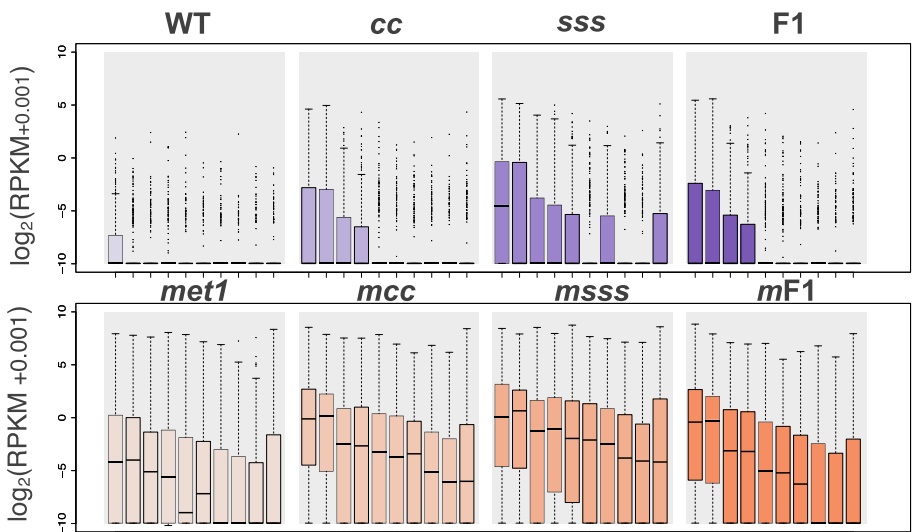

Decile ranked by $m C G$ in $m F 1$

Fig. 2 Loss of $\mathbf{m C G}$ is associated with loss of $\mathbf{m C H}$ recovery. a Genome Browser view of $\mathrm{mCG}, \mathrm{mCHG}$, and $\mathrm{mCHH}$ in $\mathrm{F} 1$ and $\mathrm{mF} 1$ plants. TEs with loss of mCG fail to restore $\mathrm{mCH}$ in $\mathrm{mF1}$ (highlighted in pink). The regions of Chr2/9,987,000-10,024,000 (left) and Chr1/16,420,326-16,439,454 (right) are shown. Gray and black arrows represent TEs and genes, respectively. b mCHG recovers in TE genes with remaining $\mathrm{mCG}$. Each TE gene (length $>1000$; $n=2422$ ) is aligned according to the mCG levels in $\mathrm{mF1}$ (left) and the methylation levels of TE genes and their flanking regions (2 kb) are shown in the form of a heatmap for each genotype (see Methods). Gray arrow represents TE gene from TSS to TTS. c Recovery of mCHG (left) and mCHH (right) is associated with the residual $\mathrm{mCG}$ in $\mathrm{mF}$. The scatter plots shown in the right panel of Fig. 1e and Fig. 1k were colored according to the residual $\mathrm{mCG}$ in $m F 1$. Red: <0.1, green: $0.1-0.3$, blue: $0.3-0.5$, and black: $>0.5$ for $\mathrm{mCG}$ in $\mathrm{mF1}$. $\mathbf{d}$ Boxplots showing the association of $\mathrm{mCH}$ recovery in $\mathrm{mF1}$ with their residual mCG (d), but not with their length (Supplementary Fig. 2c). TE genes are divided into deciles according to the mCG levels in $m F 1$, and their $m C G$ (left), $\mathrm{mCHG}$ (middle), and $\mathrm{mCHH}$ (right) levels in F1 and $m \mathrm{~F} 1$ plants are shown. TE genes with $\mathrm{mCHG}(>0.1)$ in both WT and met1-1 were analyzed ( $n=3200$ ). The $x$-axis represents $\mathrm{mCG}$ levels in $\mathrm{mF} 1$ divided into deciles and ordered from lower to higher. The centerline and box edges represent quartiles and whiskers range 1.5 times of the interquartile from the box edges. e Boxplots showing RNA expression levels of indicated genotypes. TE genes were divided into deciles according to the mCG levels in $\mathrm{mF1}$ as shown in Fig. 2d (left), and their RPKM-normalized expression levels (+0.001) are shown in log2. TE genes with $\mathrm{mCHG}(>0.1)$ in both WT and met1-1 were analyzed $(n=3200)$. Two biological replicates were examined for each genotype and one representative is shown as the two replicates show the same trend. The centerline and box edges represent quartiles and whiskers range 1.5 times of the interquartile from the box edges. Source data underlying Fig. $2 c$, $d$ are provided as a Source Data file.

\section{Discussion}

In plant genomes, both $\mathrm{mCG}$ and $\mathrm{H} 3 \mathrm{~K} 9 \mathrm{me} 2 / \mathrm{mCH}$ are important for silencing TEs, and both are enriched in TEs. Paradoxically, however, these two layers of modifications are maintained almost independently. Here, we showed that mCG directs the establishment of $\mathrm{mCH}$, even though their maintenance is rather independent. Thus, we propose that colocalization of $\mathrm{mCG}$ and $\mathrm{mCH}$ in heterochromatin reflects this mechanistic link. Importantly, the very robust targeting of $\mathrm{mCH}$ we examined in this study is independent of RNAi for both TE genes ${ }^{18}$ and active genes $^{26}$.

In contrast, RNAi is involved in the targeting of mCG. The dynamics of $\mathrm{mCG}$ have been examined after its loss in met1 mutation and reintroduction of a functional MET1 gene ${ }^{18,30,42}$. In those systems, TE genes with efficient $\mathrm{mCG}$ recovery are associated not only with $\mathrm{mCH}$ but also with siRNAs, suggesting that RNAi and/or $\mathrm{mCH}$ also enhance the establishment of mCG. When methylation is lost in both contexts in the $d d m 1$ mutants, 
a

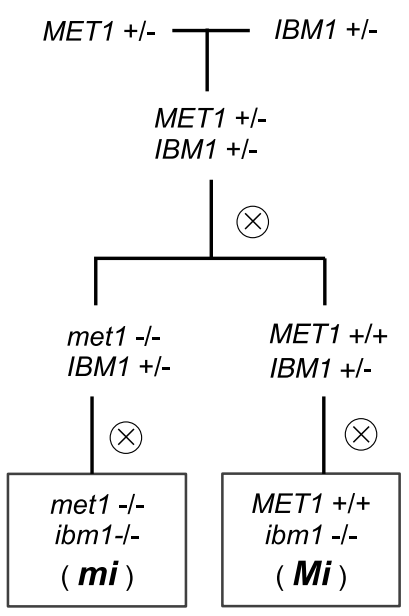

b
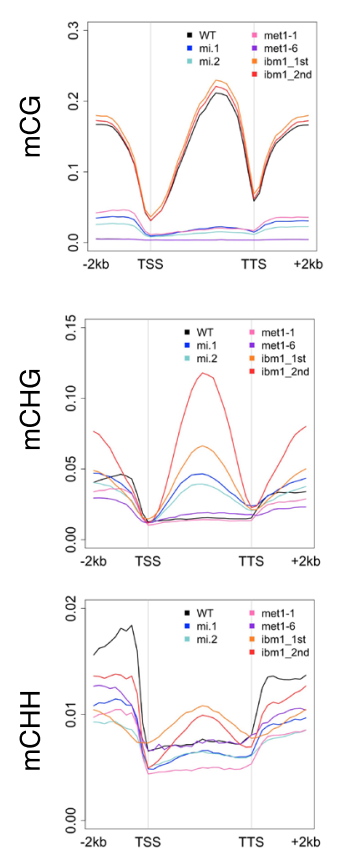

C
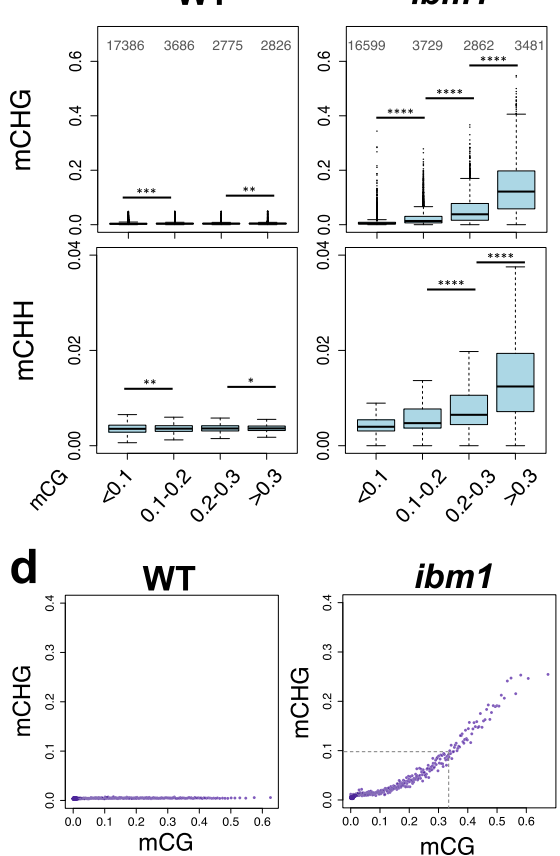

ibm1
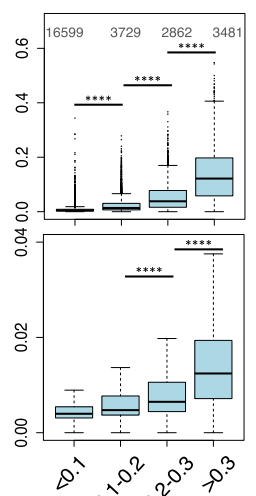
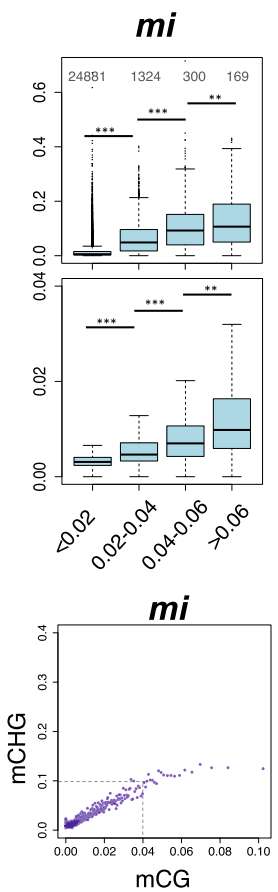

e

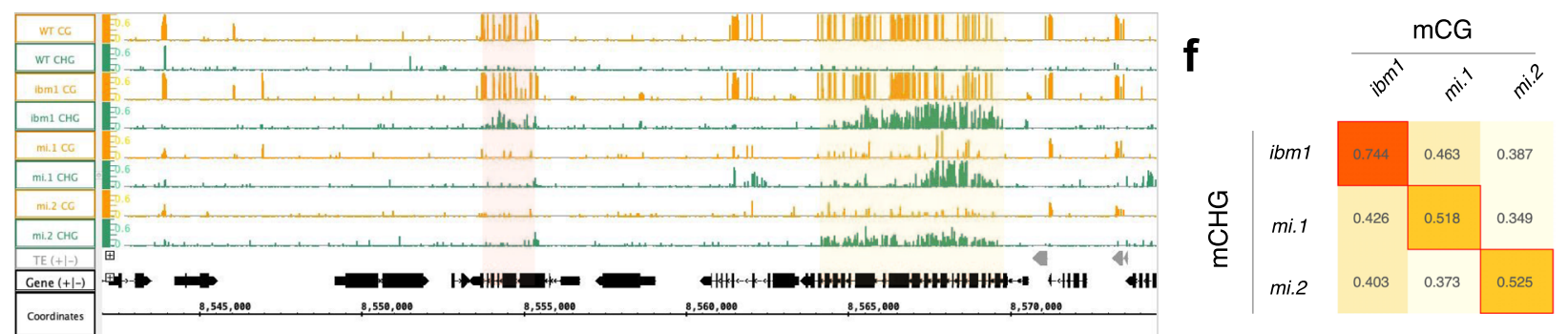

Fig. 3 Genic $\mathbf{~ m C H}$ is directed to regions with relatively high levels of $\mathbf{m C G}$. a Materials used. Starting from the cross between plants having met7-1 (met1) or ibm1-4 (ibm1) mutation in the heterozygous state, the double heterozygote was self-pollinated to fix met1 homozygote and MET1 wild-type in the F2 generation. The $i b m 1$ mutation was fixed to be homozygous in the F3 generation. The F3 plants with homozygous met7-1 mutation (mi) and homozygous wild-type MET1 (Mi) were used in this study. b Averaged $\mathrm{mCG}, \mathrm{mCHG}$, and $\mathrm{mCHH}$ profiles over genes in a WT plant, ibm1, met1 ibm1 ( $\mathrm{mi}$ ), and met1 mutants. Values for met1-6, a null mutant of MET1, are shown for comparison (GSE148753). c mCH levels are correlated with the mCG levels in both ibm1 and $\mathrm{mi}$. Genes are divided according to the $\mathrm{mCG}$ levels in the indicated genotypes and corresponding $\mathrm{mCH}$ levels are shown in boxplots $\left({ }^{\star} P<0.01\right.$, ${ }^{\star \star} P<0.001,{ }^{\star \star \star} P<0.0001$, Wilcoxon rank-sum test, two-sided). The number of genes in each class is shown on the top. The centerline and box edges represent quartiles and whiskers range 1.5 times of the interquartile from the box edges. $\mathbf{d}$ The genes were sorted by the mCG levels of indicated genotypes, grouped in bins with 50 genes, and averaged $\mathrm{mCHG}$ levels in the bins are plotted against averaged mCG levels in the corresponding bins. Mean value is plotted for each bin. e Browser view of mCG (orange) and mCHG (green) in WT, ibm1, and two individual mi mutants. The region of Chr1/ $8,542,000-8,574,500$ is shown. Gray and black arrows represent TEs and genes, respectively. The yellow shadow indicates an example of genic mCHG commonly seen in ibm1 and mi mutants. It has residual $\mathrm{mCG}$ in the mi plants. The pink shadow indicates an example of genic $\mathrm{mCHG}$ seen in ibm 1 but not in mi mutants. $\mathbf{f}$ Correlation analysis of $\mathrm{mCHG}$ and $\mathrm{mCG}$ in the $i b m 1$ and two mi individual plants. The best correlated in the individuals are boxed in red. The number in the box represents Pearson's correlation coefficient. To exclude mis-annotated TEs, the genes with mCHG in the WT (>0.05) are excluded from the analysis in panels b-d and $\mathbf{f}$ (excluded $n=1562$; analyzed $n=26,723$ ). Source data underlying Fig. 3c, d are provided as a Source Data file.

the recovery is much slower than the cases in which methylation remains in one of the two contexts ${ }^{18,31,43}$. Thus, each of $\mathrm{mCH}$ and mCG facilitates the establishment of the other.

Although such positive feedback would stabilize and enhance silent and active states, positive feedback alone would have a risk for the system to go out of control to excess. In addition to these local positive feedback mechanisms, our observation of $i b m 1$, met1, and $d d m 1$ mutants revealed global negative feedback mechanisms to control genomic $\mathrm{mCH}$ levels. Most significantly, global loss of mCG induces strong enhancement of machinery to direct $\mathrm{mCH}$ to regions with $\mathrm{mCG}$ (Fig. 3; Supplementary Fig. 3). In addition, $\mathrm{mCH}$ is also controlled negatively by the global $\mathrm{mCH}$ level (Fig. 5). Global negative feedback, combined with local positive feedback, would generate robust and balanced differentiation of active and silent genomic regions. The reactiondiffusion model is a powerful paradigm to understand pattern formation during development ${ }^{44}$, but that could also be applied to the pattern formation of active and inactive transcription units within the genome. The positive feedback mechanisms function locally to separate heterochromatic and euchromatic genomic domains, and the negative feedback by a diffusible factor(s) controls the proportion of heterochromatic regions within the genome.

Differentiation between genes and TE genes depends on IBM1 as well as on a chromatin remodeler DDM1; DDM1 is necessary for the TE-specific mCG, $\mathrm{mCH}$, and $\mathrm{H} 3 \mathrm{~K} 9 \mathrm{me}^{11,37,38,45}$, but the 

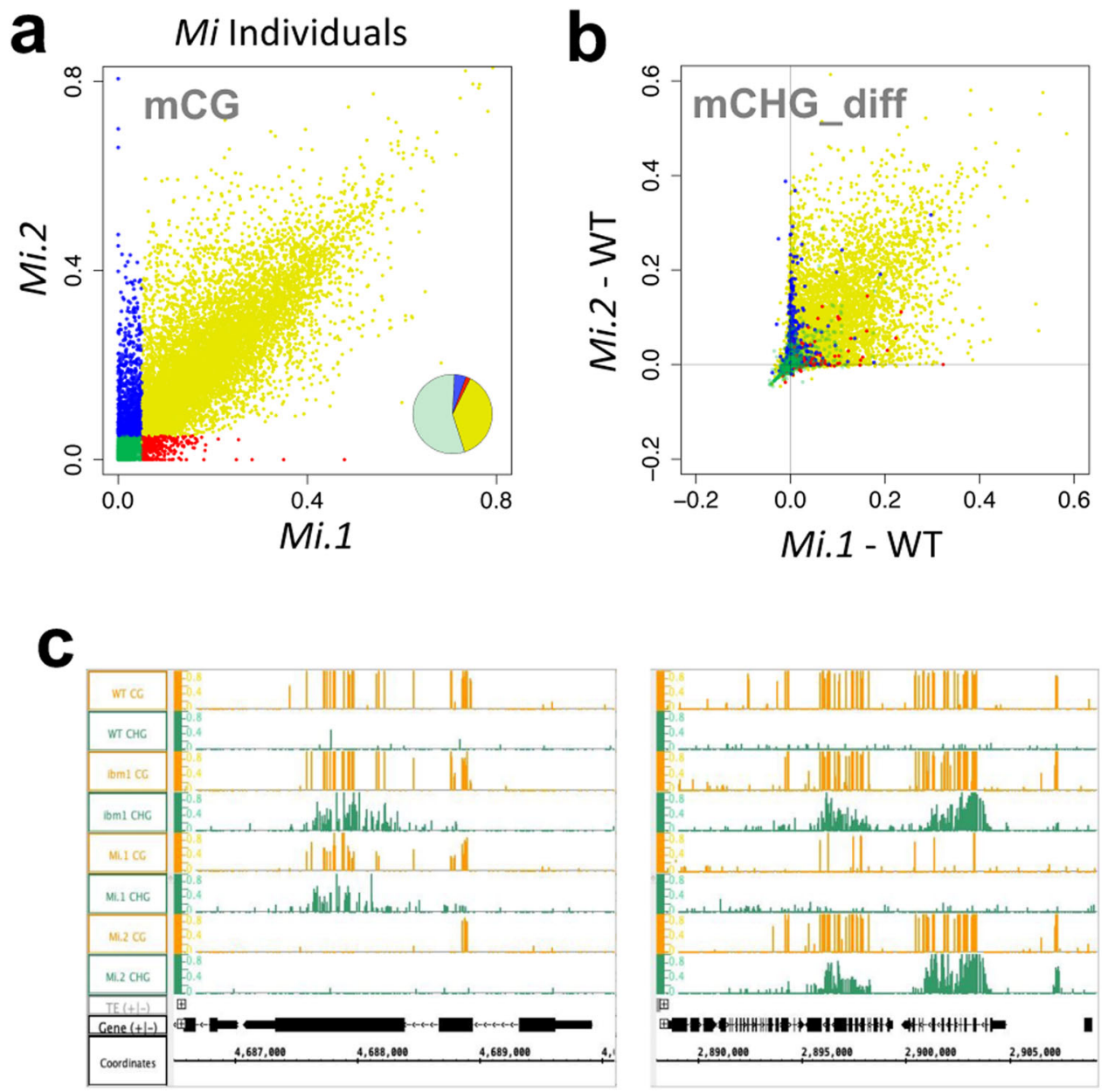

Fig. 4 Association of genic $\mathbf{m C G}$ and $\mathbf{~ m C H}$ in epigenetic variant individuals. a Differential mCG levels of genes in the two Mi individuals. The genes with the $\mathrm{mCG}$ presence $(>0.05)$ or absence $(<0.05)$ in the individuals are colored in yellow (commonly CG methylated), green (commonly CG hypomethylated), red (CG methylated only in Mi.1 individual), and blue (CG methylated only in Mi.2 individual). The ratio of each group was shown as pie chart at the right bottom. $\mathbf{b}$ The increase in genic $\mathrm{mCHG}$ in the Mi individuals. The genes are colored according to the groups in (a). c Browser view of representative variable ectopic $\mathrm{mCHG}$ in Mi individuals. The gene in the left panel shows ectopic $\mathrm{mCHG}$ in ibm1 and Mi.1, but not in Mi.2. The genes in the right panel show genic mCHG in ibm1 and Mi.2 but not in Mi.1. The regions of Chr5/4,686,500-4,690,100 (left) and Chr1/2,888,000-2,906,200 (right) are shown. Gray and black arrows below represent TEs and genes, respectively. To exclude the mis-annotated TEs, the genes with mCHG in the WT $(>0.05)$ are excluded from the analysis in $(\mathbf{a}, \mathbf{b})$ (excluded $n=1562$; analyzed $n=26,723$ ). Source data underlying Fig. $4 a$, b are provided as a Source Data file.

underlying mechanisms have remained enigmatic. It has recently been shown that DDM1 binds to heterochromatin-specific $\mathrm{H} 2 \mathrm{~A}$ variant $\mathrm{H} 2 \mathrm{~A} . \mathrm{W}$ and silences $\mathrm{TE}$ genes in combination with H2A.W ${ }^{46}$. This pathway seems to be conserved in mammals; LSH1, the mammalian ortholog of DDM1, silences repetitive sequences by deposition of heterochromatin-specific $\mathrm{H} 2 \mathrm{~A}$ variant macro- $\mathrm{H}_{2} \mathrm{~A}^{47}$. In Arabidopsis, another $\mathrm{H} 2 \mathrm{~A}$ variant, $\mathrm{H} 2 \mathrm{~A} . \mathrm{Z}$, negatively interacts with $\mathrm{mCG}^{18,41,48,49}$, and this pathway seems to be conserved to vertebrates ${ }^{23}$. The involvement of $\mathrm{H} 2 \mathrm{~A}$ variants in the local and global feedback mechanisms may also be an important target for future research.

In this work, we detected local and global crosstalk to reprogram DNA methylome. An important future challenge would be to understand the crosstalk in the context of development. DNA methylome can differ among cell types including those in stem cells and germ lines ${ }^{50-54}$. Interestingly, histone demethylase IBM1 is expressed in stem cells and reproductive cells ${ }^{25}$. In the future, dynamics would further be clarified by the single-cell genomics using preequilibrium materials, such as embryos of the first generation mutant of $I B M 1, D D M 1$, or other chromatinmodifying genes, as well as outcrossed progeny of these mutants.

\section{Methods}

Plant materials and growth conditions. The mutants met1-128, cc $(\mathrm{cmt} 2 \mathrm{cmt} 3)^{11}$ and sss (suvh4 suvh5 suvh6) ${ }^{55}$ are kind gifts from Eric Richards, Daniel Zilberman, and Judith Bender. The mutants $m c c$, msss (met1-1 suvh4 suvh5 suvh6), $m \mathrm{~F} 1, m i$ (met1-1 ibm1-4), Mi (MET1 ibm1-4), and ddm1 ibm1 were made in this study. To create the mutants $m c c, m s s s$, and $m$ F1 plants, met1-1 and $c c$ or met1-1 and $s s s$ were genetically crossed, respectively. The F1 plants were self-pollinated, and the resulting F2 plants with all homozygous mutants of met1-1 $\mathrm{cmt} 2 \mathrm{cmt} 3$ (met 1-1 $\mathrm{cmt} 2$ cmt3) and msss (met1-1 suvh4 suvh5 suvh6) were selected and used for genetic crosses to create the $m \mathrm{~F} 1$ plants. The plants were grown at $22^{\circ} \mathrm{C}(16 \mathrm{~h}$ light, $8 \mathrm{~h}$ dark), firstly on MS agar media for 1-2 weeks, and then grown on soil. $d d m 1 \mathrm{ibm} 1$ plants were grown on MS agar media until harvesting.

Whole-genome bisulfite sequencing and data processing. Genomic DNA was extracted from rosette leaves of one individual plant using the Nucleon Phytopure genomic DNA extraction kit (GE Healthcare), and whole-genome bisulfite sequencing (WGBS) was performed ${ }^{18}$. Basically, two independent biological replicates were taken except for the wild-type Col-0, met1-1, and the second generation of ibm1-4 mutant. Genomic DNA was subjected to fragmentation using a Focused Ultrasonicator (Covaris S220), and the size of 300-450 bp was gelextracted. The libraries were prepared using TruSeq DNA LT Sample Prep Kit (Illumina) and then subjected to bisulfite conversion using MethylCode Bisulfite Conversion Kit (Life Technologies). The resulting DNA was amplified using KAPA HiFi HotStart Uracil ReadyMix (Kapa Biosystems) and purified with Agencourt AMPure XP (Beckman Coulter). Raw sequence data and processed data were 

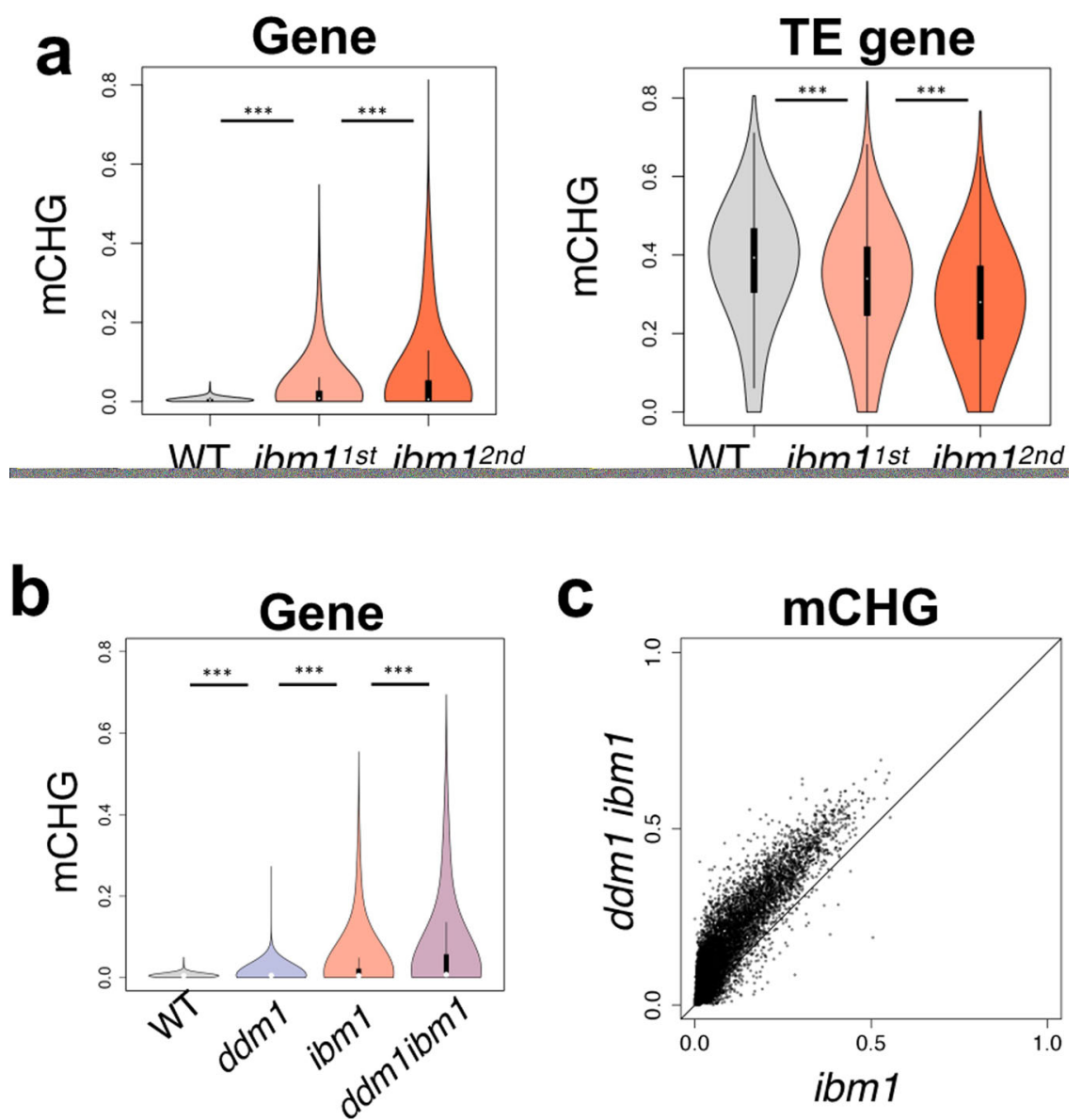

Fig. $\mathbf{5 ~} \mathbf{~ m C H}$ is controlled not only locally but also globally. a Violin plots showing the progressive accumulation of $\mathrm{mCHG}$ in genes and decrease of $\mathrm{mCHG}$ in TE genes in the ibm1 mutant ( ${ }^{\star \star \star} P<0.0001$, Wilcoxon signed-rank test, two-sided). b Violin plot showing that ddm1 mutation further enhanced the ibm1induced accumulation of $\mathrm{mCHG}$ in genes ( ${ }^{\star \star \star} P<0.0001$, Wilcoxon signed-rank test, two-sided). c The ibmi-induced genic mCHG was globally enhanced in $d d m 1 \mathrm{ibm} 1$ double mutant (line: $y=x$ ). To exclude the mis-annotated TEs, the genes with $\mathrm{mCHG}$ in the WT (>0.05) are excluded from the analysis in (a-c) (excluded $n=1562$; analyzed $n=26,723$ ). Source data underlying Fig. 5 are provided as a Source Data file.

deposited in the GEO (GSE181896). The adaptor trimming and quality filtration were performed using Trimmomatic version $0.33^{56}$. The trimmed sequences were mapped to the Arabidopsis reference genome (TAIR10) ${ }^{57}$, deduplicated, and methylation data extracted using Bismark version $0.10 .157^{58}$. The annotations of genes and TEs are based on The Arabidopsis Information Resource ${ }^{57}$. The details of the annotation of TE genes are on the TAIR website (https://www.arabidopsis.org). We used Perl scripts ${ }^{18}$ to count the numbers of methylated and total cytosines within a gene or within a 100-bp bin (For Supplementary Fig. 2a, b), and the methylation level for each context of each gene was calculated as the number of methylated cytosine within a gene divided by the number of total cytosines (weighted methylation level ${ }^{59}$ ). The numbers of methylated and unmethylated cytosines within a gene were used to extract the TE genes with statistically lower or higher $\mathrm{mCH}$ in $m \mathrm{~F} 1$ than in $\mathrm{F} 1$ in Supplementary Fig. 3 by using edgeR (v3.28.1) ${ }^{60}$ following the method in Chen et al. ${ }^{61}$. Two replicates of $F 1^{18}$ and four replicates of $m \mathrm{~F} 1$ were analyzed. The extracted TE genes were further filtered by their methylation difference between $m \mathrm{~F} 1$ and $\mathrm{F} 1$ ( $>0.1$ for $\mathrm{mCHG},>0.03$ for $\mathrm{mCHH}$ ), and between WT and met1-1 $(<0.1$ for $\mathrm{mCHG},<0.03$ for $\mathrm{mCHH})$ to exclude the TE genes for which the significant methylation change is due to met1-1 mutation. Rstudio (v1.1.463) was used to create scatter plots, box plots, and to perform statistical analysis. Genome Browser (Integrated Genome Browser ${ }^{62}$ ) was used for browser views. To create the heatmaps, TE genes and their surrounding regions $(2 \mathrm{~kb})$ were divided into 20 and 10 segments respectively, then for each segment, the value of methylated cytosines over total cytosines were calculated with Perl script. TE genes with the length $(<1000, n=1038)$ were excluded. The processed data were visualized using TreeView $3^{63}$. The methylation recovery rates shown in Fig. $1 \mathrm{~h}, \mathrm{n}$, the methylation level of each gene in the $\mathrm{F} 1$ or $m \mathrm{~F} 1$ were divided by that of corresponding background (WT or met1-1, respectively). To avoid division by values near zero, TE genes with low methylation level in WT and met1-1 $(\mathrm{CHG}<$ 0.1 for Fig. 1h; $n=318$, or $\mathrm{CHH}<0.03$ for Fig. $1 \mathrm{n} ; n=388$ ) were excluded.

RNA sequencing and data processing. Plants were surface-sterilized, grown on MS agar medium, and harvested after 12 days. Total RNAs were purified using
TRIzol RNA Isolation Reagents (Thermo), and treated with DNase I (TaKaRa). The sequencing libraries were generated using the KAPA Stranded RNA-seq Library Preparation Kit, with RNA fragmentation for $7 \mathrm{~min}$ at $94^{\circ} \mathrm{C}$. The sequencing was performed in a 150-bp pair-end. The obtained data were quality filtered by using Trimmomatic ( $v 0.33)^{56}$, and the reads were mapped to genes through STAR algorithm ${ }^{64}$, followed by bedtools $s^{65}$. After RPKM normalization, Rstudio (v1.1.463) was used to plot the expression levels. Two independent biological replicates were analyzed for each genotype.

Reporting summary. Further information on research design is available in the Nature Research Reporting Summary linked to this article.

\section{Data availability}

WGBS and RNA-seq data generated in this study were deposited in the GEO with the accession number GSE181896. WGBS data for $c c, s s s$, and F1 is available in the GEO with the accession number GSE148753. TAIR10 (https://www.arabidopsis.org) was used as the Arabidopsis reference genome. Source data are provided with this paper.

\section{Code availability}

Perl script for DNA methylation counting per gene can be available from GitHub.

Received: 12 September 2021; Accepted: 26 January 2022;

Published online: 14 February 2022

\section{References}

1. Saze, H. \& Kakutani, T. Differentiation of epigenetic modifications between transposons and genes. Curr. Opin. Plant Biol. 14, 81-87 (2011). 
2. Kim, M. Y. \& Zilberman, D. DNA methylation as a system of plant genomic immunity. Trends Plant Sci. 19, 320-326 (2014).

3. Du, J., Johnson, L. M., Jacobsen, S. E. \& Patel, D. J. DNA methylation pathways and their crosstalk with histone methylation. Nat. Rev. Mol. Cell Biol. 16, 519-532 (2015).

4. Underwood, C. J., Henderson, I. R. \& Martienssen, R. A. Genetic and epigenetic variation of transposable elements in Arabidopsis. Curr. Opin. Plant Biol. 36, 135-141 (2017).

5. Cokus, S. J. et al. Shotgun bisulphite sequencing of the Arabidopsis genome reveals DNA methylation patterning. Nature 452, 215-219 (2008).

6. Lister, R. et al. Highly integrated single-base resolution maps of the epigenome in Arabidopsis. Cell 133, 523-536 (2008).

7. Finnegan, E. J. \& Dennis, E. S. Isolation and identification by sequence homology of a putative cytosine methyltransferase from Arabidopsis thaliana. Nucleic Acids Res. 21, 2383-2388 (1993).

8. Finnegan, E. J., Peacock, W. J. \& Dennis, E. S. Reduced DNA methylation in Arabidopsis thaliana results in abnormal plant development. Proc. Natl Acad. Sci. USA 93, 8449-8454 (1996).

9. Bartee, L., Malagnac, F. \& Bender, J. Arabidopsis cmt3 chromomethylase mutations block non-CG methylation and silencing of an endogenous gene. Genes Dev. 15, 1753-1758 (2001)

10. Jackson, J. P., Lindroth, A. M., Cao, X. \& Jacobsen, S. E. Control of CpNpG DNA methylation by the KRYPTONITE histone H3 methyltransferase. Nature 416, 556-560 (2002).

11. Zemach, A. et al. The Arabidopsis nucleosome remodeler DDM1 allows DNA methyltransferases to access H1-containing heterochromatin. Cell 153, 193-205 (2013).

12. Stroud, H. et al. Non-CG methylation patterns shape the epigenetic landscape in Arabidopsis. Nat. Struct. Mol. Biol. 21, 64-72 (2014).

13. Malagnac, F., Bartee, L. \& Bender, J. An Arabidopsis SET domain protein required for maintenance but not establishment of DNA methylation. EMBO J. 21, 6842-6852 (2002).

14. Du, J. et al. Dual binding of chromomethylase domains to H3K9me2containing nucleosomes directs DNA methylation in plants. Cell 151, 167-180 (2012).

15. Johnson, L., Cao, X. \& Jacobsen, S. Interplay between two epigenetic marks. DNA methylation and histone $\mathrm{H} 3$ lysine 9 methylation. Curr. Biol. 12, 1360-1367 (2002).

16. Tariq, M. et al. Erasure of $\mathrm{CpG}$ methylation in Arabidopsis alters patterns of histone H3 methylation in heterochromatin. Proc. Natl Acad. Sci. USA 100, 8823-8827 (2003).

17. Deleris, A. et al. Loss of the DNA methyltransferase MET1 Induces H3K9 hypermethylation at PcG target genes and redistribution of $\mathrm{H} 3 \mathrm{~K} 27$ trimethylation to transposons in Arabidopsis thaliana. PLoS Genet. 8 e1003062 (2012).

18. To, T. K. et al. RNA interference-independent reprogramming of DNA methylation in Arabidopsis. Nat. Plants 6, 1455-1467 (2020).

19. Matzke, M. A. \& Mosher, R. A. RNA-directed DNA methylation: an epigenetic pathway of increasing complexity. Nat. Rev. Genet. 15, 394-408 (2014).

20. Cuerda-Gil, D. \& Slotkin, R. K. Non-canonical RNA-directed DNA methylation. Nat. Plants 2, 16163 (2016).

21. Zhang, X. et al. Genome-wide high-resolution mapping and functional analysis of DNA methylation in Arabidopsis. Cell 126, 1189-1201 (2006).

22. Zilberman, D., Gehring, M., Tran, R. K., Ballinger, T. \& Henikoff, S. Genomewide analysis of Arabidopsis thaliana DNA methylation uncovers an interdependence between methylation and transcription. Nat. Genet. 39, 61-69 (2007).

23. Zemach, A., McDaniel, I. E., Silva, P. \& Zilberman, D. Genome-wide evolutionary analysis of eukaryotic DNA methylation. Science 328, 916-919 (2010).

24. To, T. K., Saze, H. \& Kakutani, T. DNA methylation within transcribed regions. Plant Physiol. 168, 1219-1225 (2015).

25. Saze, H., Shiraishi, A., Miura, A. \& Kakutani, T. Control of genic DNA methylation by a jmjC domain-containing protein in Arabidopsis thaliana. Science 319, 462-465 (2008).

26. Miura, A. et al. An Arabidopsis jmjC domain protein protects transcribed genes from DNA methylation at CHG sites. EMBO J. 28 , 1078-1086 (2009).

27. Inagaki, S. et al. Autocatalytic differentiation of epigenetic modifications within the Arabidopsis genome. EMBO J. 29, 3496-3506 (2010).

28. Kankel, M. W. et al. Arabidopsis MET1 cytosine methyltransferase mutants. Genetics 163, 1109-1122 (2003).

29. Xiao, W. et al. DNA methylation is critical for Arabidopsis embryogenesis and seed viability. Plant Cell 18, 805-814 (2006).

30. Catoni, M. et al. DNA sequence properties that predict susceptibility to epiallelic switching. EMBO J. 36, 617-628 (2017).
31. Kakutani, T., Munakata, K., Richards, E. J. \& Hirochika, H. Meiotically and mitotically stable inheritance of DNA hypomethylation induced by ddm1 mutation of Arabidopsis thaliana. Genetics 151, 831-838 (1999).

32. Mathieu, O., Reinders, J., Caikovski, M., Smathajitt, C. \& Paszkowski, J. Transgenerational stability of the Arabidopsis epigenome is coordinated by CG methylation. Cell 130, 851-862 (2007).

33. Schmitz, R. J. et al. Transgenerational epigenetic instability is a source of novel methylation variants. Science 334, 369-373 (2011).

34. Gallego-Bartolomé, J. et al. Co-targeting RNA polymerases IV and V promotes efficient de novo DNA methylation in Arabidopsis. Cell 176 1068-1082 (2019). e19.

35. Saze, H., Mittelsten Scheid, O. \& Paszkowski, J. Maintenance of CpG methylation is essential for epigenetic inheritance during plant gametogenesis. Nat. Genet. 34, 65-69 (2003).

36. Stroud, H., Greenberg, M. V. C., Feng, S., Bernatavichute, Y. V. \& Jacobsen, S. E. Comprehensive analysis of silencing mutants reveals complex regulation of the Arabidopsis methylome. Cell 152, 352-364 (2013).

37. Vongs, A., Kakutani, T., Martienssen, R. A. \& Richards, E. J. Arabidopsis thaliana DNA methylation mutants. Science 260, 1926-1928 (1993).

38. Jeddeloh, J. A., Stokes, T. L. \& Richards, E. J. Maintenance of genomic methylation requires a SWI2/SNF2-like protein. Nat. Genet. 22, 94-97 (1999).

39. Saze, H. \& Kakutani, T. Heritable epigenetic mutation of a transposon-flanked Arabidopsis gene due to lack of the chromatin-remodeling factor DDM1. EMBO J. 26, 3641-3652 (2007).

40. Ito, T. et al. Genome-wide negative feedback drives transgenerational DNA methylation dynamics in Arabidopsis. PLoS Genet. 11, e1005154 (2015)

41. Coleman-Derr, D. \& Zilberman, D. Deposition of histone variant H2A.Z within gene bodies regulates responsive genes. PLoS Genet. 8, e1002988 (2012).

42. Rigal, M. et al. Epigenome confrontation triggers immediate reprogramming of DNA methylation and transposon silencing in Arabidopsis thaliana F1 epihybrids. Proc. Natl Acad. Sci. USA 113, E2083-E2092 (2016).

43. Teixeira, F. K. et al. A role for RNAi in the selective correction of DNA methylation defects. Science 323, 1600-1604 (2009).

44. Kondo, S. \& Miura, T. Reaction-diffusion model as a framework for understanding biological pattern formation. Science 329, 1616-1620 (2010).

45. Gendrel, A. V., Lippman, Z., Yordan, C., Colot, V. \& Martienssen, R. A Dependence of heterochromatic histone $\mathrm{H} 3$ methylation patterns on the Arabidopsis gene DDM1. Science 297, 1871-1873 (2002)

46. Osakabe, A. et al. The chromatin remodeler DDM1 prevents transposon mobility through deposition of histone variant H2A.W. Nat. Cell Biol. 23, 391-400 (2021)

47. $\mathrm{Ni}, \mathrm{K}$. et al. LSH mediates gene repression through macroH2A deposition. Nat. Commun. 11, 5647 (2020)

48. Zilberman, D., Coleman-Derr, D., Ballinger, T. \& Henikoff, S. Histone H2A.Z and DNA methylation are mutually antagonistic chromatin marks. Nature 456, 125-129 (2008).

49. Nie, W. F. et al. Histone acetylation recruits the SWR1 complex to regulate active DNA demethylation in Arabidopsis. Proc. Natl Acad. Sci. USA 116, 16641-16650 (2019)

50. Slotkin, R. K. et al. Epigenetic reprogramming and small RNA silencing of transposable elements in pollen. Cell 136, 461-472 (2009).

51. Baubec, T., Finke, A., Mittelsten Scheid, O. \& Pecinka, A. Meristem-specific expression of epigenetic regulators safeguards transposon silencing in Arabidopsis. EMBO Rep. 15, 446-452 (2014).

52. Kawakatsu, T. et al. Unique cell-type-specific patterns of DNA methylation in the root meristem. Nat. Plants 2, 16058 (2016).

53. Bouyer, D. et al. DNA methylation dynamics during early plant life. Genome Biol. 18, 179 (2017).

54. Gutzat, R. et al. Arabidopsis shoot stem cells display dynamic transcription and DNA methylation patterns. EMBO J. 39, e103667 (2020).

55. Ebbs, M. L. \& Bender, J. Locus-specific control of DNA methylation by the Arabidopsis SUVH5 histone methyltransferase. Plant Cell 18, 1166-1176 (2006).

56. Bolger, A. M., Lohse, M. \& Usadel, B. Trimmomatic: a flexible trimmer for Illumina sequence data. Bioinformatics 30, 2114-2120 (2014).

57. Lamesch, P. et al. The Arabidopsis Information Resource (TAIR): improved gene annotation and new tools. Nucleic Acids Res. 40, D1202-D1210 (2012).

58. Krueger, F. \& Andrews, S. R. Bismark: a flexible aligner and methylation caller for Bisulfite-Seq applications. Bioinformatics 27, 1571-1572 (2011).

59. Schultz, M. D., Schmitz, R. J. \& Ecker, J. R. 'Leveling' the playing field for analyses of single-base resolution DNA methylomes. Trends Genet. 28, 583-585 (2012).

60. Robinson, M. D., McCarthy, D. J. \& Smyth, G. K. edgeR: a Bioconductor package for differential expression analysis of digital gene expression data. Bioinformatics 26, 139-140 (2010). 
61. Chen, Y., Pal, B., Visvader, J. E. \& Smyth, G. K. Differential methylation analysis of reduced representation bisulfite sequencing experiments using edgeR. F1000Res. 6, 2055 (2017).

62. Nicol, J. W., Helt, G. A., Blanchard, S. G. Jr., Raja, A. \& Loraine, A. E. The Integrated Genome Browser: free software for distribution and exploration of genome-scale datasets. Bioinformatics 25, 2730-2731 (2009).

63. Keil, C. et al. Treeview 3.0 (beta 1) - visualization and analysis of large data matrices. Zenodo https://doi.org/10.5281/zenodo.1303402 (2018).

64. Dobin, A. et al. STAR: ultrafast universal RNA-seq aligner. Bioinformatics 29, 15-21 (2013).

65. Quinlan, A. R. \& Hall, I. M. BEDTools: a flexible suite of utilities for comparing genomic features. Bioinformatics 26, 841-842 (2010).

\section{Acknowledgements}

We thank Eric Richards and Robert Schmitz for critical comments on the manuscript, and Judith Bender, Robert Fischer, Eric Richards, and Daniel Zilberman for sharing mutant strains. Computations were partially performed on the NIG supercomputer at NIG, Japan. Supported by grants from, Japanese Ministry of Education, Culture, Sports, Science and Technology (26221105, 15H05963, 19H00995, and 21H04977 to T.K., 19H05740 and 17K15059 to T.K.T.), CREST Grant, Japan (JPMJCR15O1 to T.K.), Systems Functional Genetics Project of the Transdisciplinary Research Integration Center, ROIS, Japan (to Y.T. and T.K.).

\section{Author contributions}

T.K.T., C.Y., S.O., and T.K. designed the study. T.K.T., C.Y., S.O., S.T., A.K., Y.T., and T.K. performed the experiments. T.K.T., C.Y., and S.O. analyzed the data. T.K.T. and

T.K. wrote the paper incorporating comments from the other authors.

\section{Competing interests}

The authors declare no competing interests.

\section{Additional information}

Supplementary information The online version contains supplementary material available at https://doi.org/10.1038/s41467-022-28468-5.

Correspondence and requests for materials should be addressed to Taiko Kim To or Tetsuji Kakutani.

Peer review information Nature Communications thanks Daniel Bouyer, Jose GutierrezMarcos, and Olivier Mathieu for their contribution to the peer review of this work. Peer reviewer reports are available.

Reprints and permission information is available at http://www.nature.com/reprints

Publisher's note Springer Nature remains neutral with regard to jurisdictional claims in published maps and institutional affiliations.

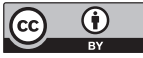

Open Access This article is licensed under a Creative Commons Attribution 4.0 International License, which permits use, sharing, adaptation, distribution and reproduction in any medium or format, as long as you give appropriate credit to the original author(s) and the source, provide a link to the Creative Commons license, and indicate if changes were made. The images or other third party material in this article are included in the article's Creative Commons license, unless indicated otherwise in a credit line to the material. If material is not included in the article's Creative Commons license and your intended use is not permitted by statutory regulation or exceeds the permitted use, you will need to obtain permission directly from the copyright holder. To view a copy of this license, visit http://creativecommons.org/ licenses/by/4.0/.

(C) The Author(s) 2022 